\title{
The Midlatitude Continental Convective Clouds Experiment (MC3E) sounding network: operations, processing and analysis
}

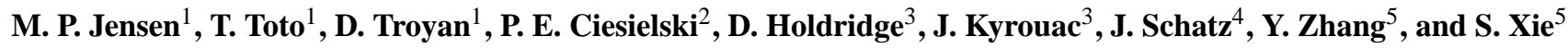 \\ ${ }^{1}$ Brookhaven National Laboratory, Upton, NY, USA \\ ${ }^{2}$ Colorado State University, Fort Collins, CO, USA \\ ${ }^{3}$ Argonne National Laboratory, Argonne, IL, USA \\ ${ }^{4}$ ARM Climate Research Facility, Southern Great Plains site, Billings, OK, USA \\ ${ }^{5}$ Lawrence Livermore National Laboratory, Livermore, CA, USA \\ Correspondence to: M. P. Jensen (mjensen@bnl.gov)
}

Received: 20 May 2014 - Published in Atmos. Meas. Tech. Discuss.: 12 September 2014

Revised: 9 December 2014 - Accepted: 19 December 2014 - Published: 27 January 2015

\begin{abstract}
The Midlatitude Continental Convective Clouds Experiment (MC3E) took place during the spring of 2011 centered in north-central Oklahoma, USA. The main goal of this field campaign was to capture the dynamical and microphysical characteristics of precipitating convective systems in the US Central Plains. A major component of the campaign was a six-site radiosonde array designed to capture the large-scale variability of the atmospheric state with the intent of deriving model forcing data sets. Over the course of the 46-day MC3E campaign, a total of 1362 radiosondes were launched from the enhanced sonde network. This manuscript provides details on the instrumentation used as part of the sounding array, the data processing activities including quality checks and humidity bias corrections and an analysis of the impacts of bias correction and algorithm assumptions on the determination of convective levels and indices. It is found that corrections for known radiosonde humidity biases and assumptions regarding the characteristics of the surface convective parcel result in significant differences in the derived values of convective levels and indices in many soundings. In addition, the impact of including the humidity corrections and quality controls on the thermodynamic profiles that are used in the derivation of a large-scale model forcing data set are investigated. The results show a significant impact on the derived large-scale vertical velocity field illustrating the importance of addressing these humidity biases.
\end{abstract}

\section{Introduction}

The Midlatitude Continental Convective Clouds Experiment (MC3E; Jensen et al., 2010) was a joint field campaign between the US Department of Energy's Atmospheric Radiation Measurement (ARM) Program (Mather and Voyles, 2013; Ackerman and Stokes, 2003; Stokes and Schwartz, 1994; http://www.arm.gov) and NASA's Global Precipitation Measurement Mission's (GPM) Ground Validation Program (Hou et al., 2014; http://www.nasa.gov/mission_pages/GPM/ main/). It took place from 22 April through 6 June 2011 centered at the ARM Southern Great Plains (SGP) Facility in north-central Oklahoma. The campaign utilized the largest-to-date ground-based observing infrastructure in the central United States, including recent instrumentation upgrades provided through the American Recovery and Reinvestment Act of 2009, combined with remote sensing and in situ aircraft, additional radar and in situ precipitation instrumentation and an extensive sounding array. The overarching goal of the field campaign was to construct a comprehensive data set of surface-, aircraft- and satellite-based observations targeting processes important for the parameterization of convection in large-scale models and the retrieval of precipitation by spaceborne sensors over land.

A major component of the MC3E field campaign was the deployment of an enhanced radiosonde array designed to capture the large-scale variability of the vertical profile of atmospheric state variables (pressure, temperature, humidity and winds). The radiosonde array included six sites 
launching radiosondes at $3-6 \mathrm{~h}$ sampling intervals. This network (Fig. 1, Table 1) covered an area of approximately $300 \times 300 \mathrm{~km}$ with five perimeter sounding launch sites and one central launch location.

The large-scale sounding array facilitates the description of the variability of the atmospheric state in space over the scale of a global climate model grid box and over the diurnal cycle. A major motivation for the sounding array is to provide large-scale forcing fields, through traditional budget analyses (e.g., Yanai et al., 1973; Johnson, 1984; Johnson and Ciesielski, 2013) and constrained variational objective analyses (Zhang and Lin, 1997; Zhang et al., 2001; Xie et al., 2010; Xie et al., 2014), that can be used for singlecolumn model (SCM) and cloud-resolving model (CRM) studies (Klein and Del Genio, 2006).

Specifics of the sounding operations during the MC3E field campaign will be presented in Sect. 2. Details of the data processing will be discussed in Sect. 3, including data quality controls and corrections for known sounding humidity biases. Section 4 will discuss the sensitivity to measurement uncertainties and algorithm assumptions of the calculation of several important indices for convective studies and the derivation of a large-scale model forcing data set.

\section{MC3E sounding operations}

\subsection{Background}

The SGP ARM site was established in the spring of 1992 and consists of an array of in situ and remote sensing instrument clusters deployed over a $150 \times 150 \mathrm{~km}$ area in north-central Oklahoma and south-central Kansas (http://www.arm.gov/ sites/sgp). The site was designed to measure cloud, radiation, aerosol and atmospheric state properties over long timescales in a region that experiences a wide variety of meteorological conditions. As part of this measurement suite, the ARM program has launched radiosondes regularly from the SGP Central Facility $\left(\mathrm{C} 1 ; 36.695^{\circ}\right.$ latitude, $-97.485^{\circ}$ longitude $)$ since 14 July 1992. From August 2001 through the present, routine operations have consisted of four daily launches at approximately 00:30, 06:30, 11:30 and 17:30 local time. These launch times were chosen to complement the standard launch times (07:00 and 19:00 local time) by the National Weather Service. During special intensive observation periods (IOPs) the sonde launch frequency is often increased to 3-hourly at C1 and other sites in the SGP region as was done in the 1997 Summer Single Column Model IOP (Ghan et al., 2000; Xu et al., 2002) the March 2000 ARM Cloud IOP (Dong et al., 2002; Xie et al., 2005), and the 2007 Cloud and Land Surface Interaction Campaign (CLASIC, Miller et al., 2007).

\subsection{Siting}

During MC3E, five additional sounding locations were deployed. These sites were chosen in order to provide a suf-

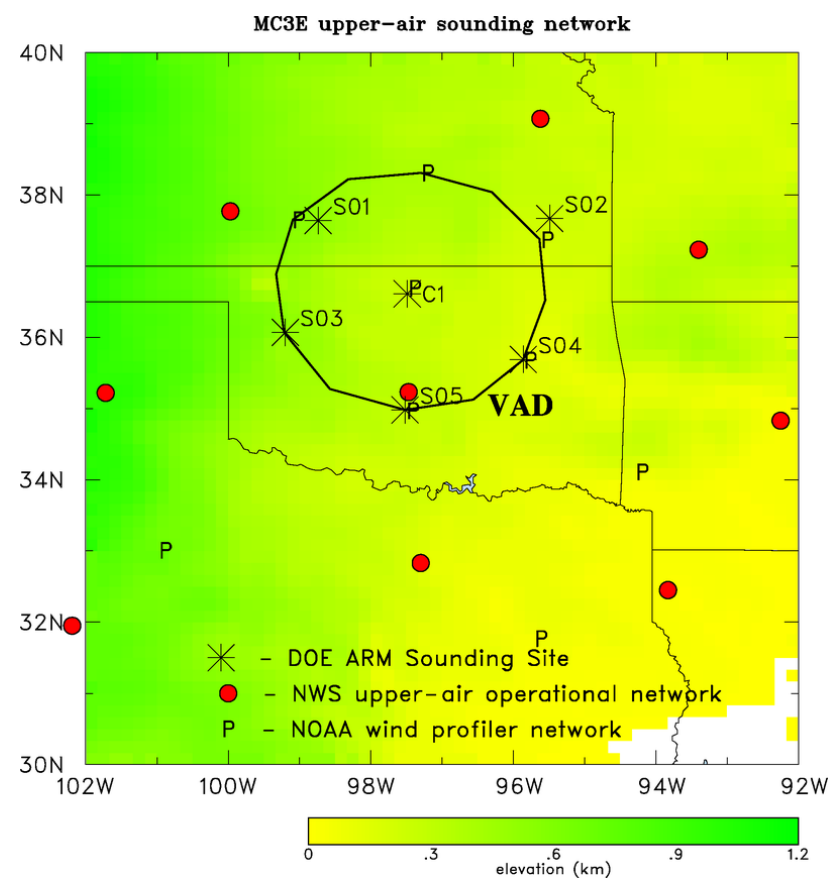

Figure 1. Map of the MC3E ground-based observing domain including the outer sounding domain: Central Facility [C1 Lamont, Oklahoma (OK) $36.695^{\circ}$ latitude, $-97.485^{\circ}$ longitude] S1 Pratt, Kansas (KS) [37.7, -98.75]; S2 Chanute, KS [37.674, -95.488], S3 Vici, OK [36.071, -99.204]; S4 Morris, OK [35.687, -95.856]; S5 Purcell, OK [34.985, -97.522]. Also shown on this map are surrounding sites from the NWS operational sonde network and NOAA profiler network. Variational analysis domain (VAD) is indicated with a polygon. Shading indicates elevation according to the scale at bottom.

ficiently large sampling area in order to capture variability on scales larger than that of the grid size of a typical global climate model $(\sim 150 \mathrm{~km} \times 150 \mathrm{~km})$ and to apply the constrained variational objective analysis (Zhang and Lin, 1997; Zhang et al., 2001) in order to provide large-scale forcing fields for modeling studies. Figure 1 shows a map of the MC3E enhanced sounding network including sounding stations: Central Facility at Lamont, OK (C1), Pratt, KS (S1), Chanute, KS (S2), Vici, OK (S3), Morris, OK (S4) and Purcell, OK (S5). Details of the locations of these stations are given in Table 1. Also shown on this map are surrounding sites from the National Weather Service (NWS) operational sonde network and NOAA wind profiler network. Data from the enhanced MC3E sites and surrounding networks are used to compute budgets and large-scale forcing fields over the variational analysis domain (VAD) shown by the polygon in Fig. 1.

Using a 6-day Weather Research and Forecasting (WRF) model simulation of convection over the SGP region (at $500 \mathrm{~m}$ horizontal resolution, 50 vertical levels and $3 \mathrm{~h}$ sampling intervals), we examined several different possible configurations for the sounding array by comparing the large- 
Table 1. Summary of MC3E sounding array locations.

\begin{tabular}{llllc}
\hline $\begin{array}{l}\text { Site } \\
\text { Designator }\end{array}$ & City, State & $\begin{array}{l}\text { Latitude } \\
(\text { deg. North) }\end{array}$ & $\begin{array}{l}\text { Longitude } \\
\text { (deg. West) }\end{array}$ & $\begin{array}{c}\text { Elevation } \\
(\mathrm{m})\end{array}$ \\
\hline C1 & Lamont, Oklahoma (OK) & 36.695 & 97.485 & 315 \\
S1 & Pratt, Kansas (KS) & 37.7 & 98.75 & 594 \\
S2 & Chanute, KS & 37.674 & 95.488 & 297 \\
S3 & Vici, OK & 36.071 & 99.204 & 628 \\
S4 & Morris, OK & 35.687 & 95.586 & 217 \\
S5 & Purcell, OK & 34.985 & 97.522 & 344 \\
\hline
\end{tabular}

scale divergence calculated using a budget analysis based on array soundings compared to the high-resolution model divergence calculated over the arrays. The results showed that if the NOAA operational sounding and wind profiler networks over the central United States (shown in Fig. 1) are included in the derivation of the large-scale forcing data set, the VAD network results in relatively small biases and root mean square errors compared to other network configurations that were logistically available.

In addition to the scientific justification for the selection of the radiosonde launch locations, there were important logistical considerations. The security and safety of the operational staff was of the highest priority. For this reason, selected sites needed to be secure for both the sonde staff and equipment, and the nearby availability of a storm shelter was required in case of severe weather. An additional important consideration was the ability to leverage existing infrastructure. The three southernmost sounding locations (S3 Vici, OK; S4 Morris, OK; S5 Purcell, OK) were former ARM boundary facility sites that were historically used as sounding locations for IOPs. These sites still have the infrastructure required for regular radiosonde launches, including power, communications and housing for radiosonde equipment. The northernmost sites (S1 Pratt, KS; S2 Chanute, KS) were new sites located at local airports where space and facilities existed and were rented for use during the campaign.

\subsection{Instrumentation}

All sounding sites used Vaisala model RS92-SGP radiosondes attached to a $350 \mathrm{~g}$ helium-filled meteorological balloon. The RS92-SGP uses a capacitive wire temperature sensor with an accuracy of $0.5^{\circ} \mathrm{C}$ over a range from +60 to $-90^{\circ} \mathrm{C}$, a thin-film capacitor, a heated twin humidity sensor with $5 \%$ uncertainty in relative humidity and a silicon pressure sensor with a maximum uncertainty of $1 \mathrm{hPa}$. The RS92-SGP sondes used in MC3E were manufactured in 2010-2011. The RS92-SGP data were received and recorded by Vaisala DigiCORA sounding systems at all sites. Three of these systems were of the more recent generation MW21 type (C1: Lamont, OK; S1: Pratt, KS; S2: Chanute, KS) and the remaining three sites (S3: Vici, OK; S4: Morris, OK; S5: Purcell, OK) used older MW15 systems. The older generation systems were not capable of running the latest Vaisala processing software (v3.64) with its associated corrections for humidity biases. For consistency, the v3.64 processing was turned off in the newer systems, and the humidity corrections were applied during our post-processing procedures (see Sect. 3.1). Vaisala ground check sets GC25 were used at all sites providing a pre-launch check on the radiosonde calibration and a reconditioning of the RS92-SGP relative humidity sensor. The desiccant in the GC25 ground check set was changed weekly or whenever the radiosonde relative humidity $(\mathrm{RH})$ reading, while in the GC25, exceeded $1 \%$. Temperature, humidity, wind and pressure systems (THWAPS; Ritsche and Prell, 2011), which include Vaisala HMP233 temperature and humidity sensors, a Vaisala Model PTB201A digital barometer and an R.M. Young model 05103 wind monitor, also provided an additional calibration point at the surface at the C1, S3, S4, S5 sites. At the S1 site, Vaisala HMP233 microprocessor transmitters were used for the measurement of surface relative humidity and temperature. For the S2 site, surface meteorology observations were available from a National Weather Service Automated Surface Observing System (ASOS) station used by the airport. In order to facilitate the launch of a balloon by a single technician, a specially designed balloon launch cart was used that serves to hold the balloon in place while it is inflated and the radiosonde unit is attached.

To provide additional constraint on the radiosonde humidity observations, we used a nearby measurement of the total column water vapor amount in order to scale the integrated water vapor from the radiosonde when appropriate (see more details in Sect. 3.1). At the Central Facility, C1, observations from a two-channel $(23.8$ and $31.4 \mathrm{GHz}) \mathrm{mi}-$ crowave radiometer (MWR; Morris, 2006) were used in a physical retrieval (MWRRET; Turner et al., 2007) to produce a time series (time steps of approximately $30 \mathrm{~s}$ ) of precipitable water vapor (PWV) and liquid water path measurements. MWRs were not available for the outer sites of the radiosonde array. As an alternative, we investigated the use of PWV retrieved from GPS signal propagation delay measurements (e.g., Bevis et al., 1992) from the nearest SuomiNet (www.suominet.ucar.edu; Ware et al., 2000) GPS station. For the $\mathrm{C} 1, \mathrm{~S} 3$ and $\mathrm{S} 4$ sites, the nearest GPS station was within 

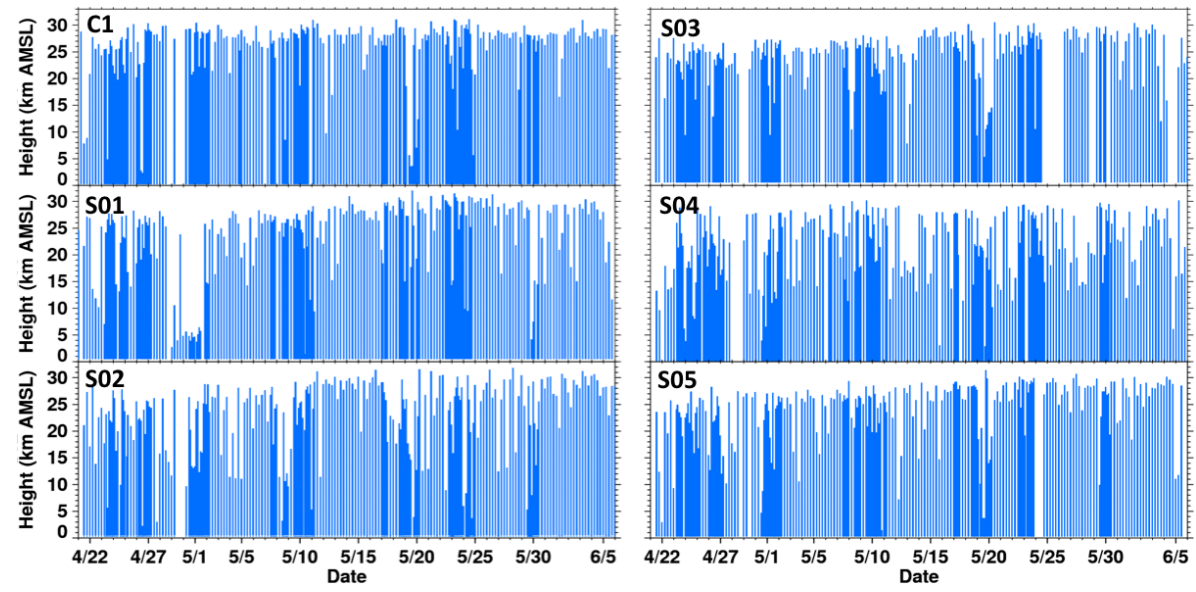

Figure 2. Sounding inventory summarizing the time of each launch and maximum height attained by each sonde for C1 (top), S1, S2, S3, S4, S5 (bottom).

$1 \mathrm{~km}$ of the sonde launch site. For the $\mathrm{S} 1, \mathrm{~S} 2$ and $\mathrm{S} 3$ sites the nearest GPS station was between 30 and $125 \mathrm{~km}$ from the sounding site (note that, as will be discussed in Sect. 3.1 and illustrated in Fig. 5, it was found that the GPS observations induced a dry bias in the corrected humidity profiles, and so we did not use them for scaling).

\subsection{Data collection summary}

Normally, under non-convective weather conditions, each of the six sites launched four soundings per day following the current schedule for routine operations at the SGP C1. On days for which convective conditions were forecast, sounding operations switched to a high-frequency launch schedule by adding launches at approximately 03:30, 09:30, 15:30, and 21:30 local time. In some cases, the high-frequency launch schedule was aborted at the discretion of the mission scientists if favorable conditions did not materialize. A launch was deemed successful if the balloon reached a pressure level of $700 \mathrm{hPa}$. If the balloon burst below this level, a second launch was attempted.

Over the course of the 6-week MC3E field campaign, a total of 1362 radiosondes were launched from the six sites. Figure 2 provides a visual inventory of the soundings, depicting information on the height attained for each launch and the frequency of sonde launches (by how close together the vertical bars are). Over the course of the campaign, a total of 8 days (24, 25, 27 April; 1, 2, 10, 11, 19, 20, 24 May) included a full high-frequency schedule of eight soundings. Seven additional days $(8,9,17,23,25,30,31$ May) included 5-7 soundings per day. Four soundings per day were launched on the remaining days of the field campaign. Note that an individual site may have fewer soundings than indicated by this list due to severe local weather or other operational considerations. During post-processing of the soundings, several data quality issues were identified and corrected

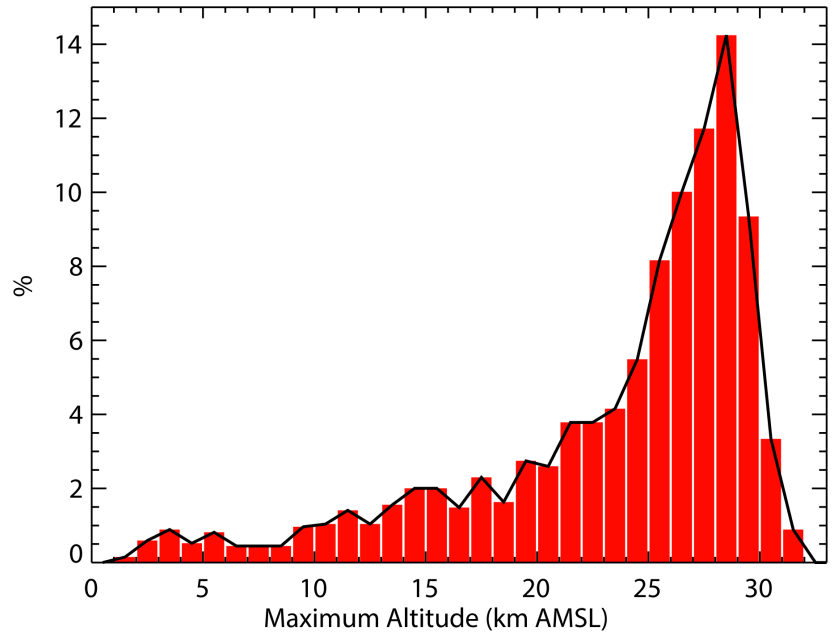

Figure 3. Frequency of occurrence (normalized by the total number of soundings) of the maximum height obtained by MC3E soundings, for all sites.

when possible. A total of 14 soundings contained data quality issues (e.g., very early termination, unrealistic temperature/humidity variations) that were not correctable. In order to further summarize the success of the sounding operations, Table 2 indicates the number of soundings that sampled through a typical depth of the troposphere for each site. This table indicates that $90 \%$ of the soundings launched during MC3E sampled at least through the depth of the troposphere. Figure 3 shows the frequency of occurrence (normalized by the total number of soundings) of the maximum altitude obtained during $\mathrm{MC} 3 \mathrm{E}$. 
Table 2. Summary of termination height of MC3E soundings. 10th percentile tropopause height is taken from Rapid Update Cycle (RUC) analysis for period from 22 April through 6 June 2011. Early termination indicates soundings that did not sample above the 10th percentile tropopause height. The total sounding number here does not include the 14 sondes that were not correctable (see text for additional details).

\begin{tabular}{llll}
\hline $\begin{array}{l}\text { Radiosonde } \\
\text { Site }\end{array}$ & $\begin{array}{l}\text { 10th percentile } \\
\text { tropopause height }[\mathrm{hPa}]\end{array}$ & $\begin{array}{l}\text { Total \# } \\
\text { soundings }\end{array}$ & $\begin{array}{l}\text { \# Early termination } \\
\text { soundings (\% of total) }\end{array}$ \\
\hline C1 - ARM Central Facility, Lamont, OK & 153.0 & 229 & $14(6.1)$ \\
S1 - Pratt, KS & 145.4 & 228 & $27(11.8)$ \\
S2 - Chanute, KS & 154.8 & 230 & $34(14.8)$ \\
S3 - Vici, OK & 143.3 & 209 & $13(6.2)$ \\
S4 - Morris, OK & 159.7 & 227 & $28(12.3)$ \\
S5 - Purcell, OK & 149.5 & 225 & $19(8.4)$ \\
\hline Total & & 1348 & $135(10.0)$ \\
\hline
\end{tabular}

\section{Radiosonde data processing}

\subsection{Automatic data quality checks}

The Vaisala RS92-SGP sonde reports temperature, dew point, relative humidity, barometric pressure, wind speed and wind direction every $2 \mathrm{~s}$ throughout the radiosonde flight. The sounding software terminates data collection for a flight under one of the following conditions: the barometric pressure is observed to increase by more than $50 \mathrm{hPa}$ (balloon has burst), several temperature measurements are missing in a row, a transmission signal is no longer received from the sounding for more than $720 \mathrm{~s}$ or a sensor failure is detected. The ARM program routinely includes some automated data quality checks that are based on predefined limits for the maximum, minimum and sample-to-sample change (delta) in the values of each raw variable. For the SGP locale, these limits are shown in Table 3 (Holdridge et al., 2011). One of these routine checks failed at one of more levels in $39 \%$ of the soundings launched during MC3E. Table 4 shows the frequency of occurrence of routine data quality check failure based on the parameters defined in Table 3. Although a large percentage of sondes experienced data quality check failures at some point, the individual failures represented only a small fraction (less than $4 \%$ total of the sonde measurements at any level). In general, failed out of bounds quality checks occurred for only a few levels in a given sounding and are dominated by missing wind observations in the upper troposphere.

\subsection{Corrections to sounding humidity observations}

A great deal of previous work has been devoted to defining and minimizing sources of error in Vaisala RS92-SGP humidity measurements including bias (systematic) errors, random errors and sensor time-lag errors (e.g., Milosevich et al., 2009, hereafter M09, and references therein). In particular, M09 performed a comparison of RS92-SGP radiosonde water vapor measurements with three reference instruments (cryogenic frost-point hygrometer, microwave radiometer and surface-based relative humidity probes with National Institute of Standards and Technology traceable calibrations) with well-defined accuracies. They define six separate contributions to errors in the RS92-SGP humidity measurements including (1) a mean calibration bias related to the accuracy of the Vaisala calibration model and calibration references, (2) random variability in the production of individual sondes, (3) time-lag errors caused by the slow response of the sensor at low temperatures, (4) a dry bias due to heating of the sensor by solar radiation, (5) biases related to improper application of ground check procedures and (6) precision errors due to round-off of $\mathrm{RH}$ to integer values.

Based on their comparative study, M09 provide an empirical mean bias correction for the RS92-SGP humidity profiles. The algorithm involves first applying a previously defined correction for the time-lag errors of the humidity sensor (Milosevich et al., 2004). Next, the empirical mean bias correction (defined in Fig. 9 and Table 1 in M09) is applied. Finally, since the M09 daytime correction was constructed for a solar zenith angle of $66^{\circ}$, daytime soundings require a final adjustment to account for differences from this angle. The M09 corrections are applied in the ARM SONDEADJUST value-added product (Troyan, 2012b) for the ARM SGP Central Facility site. We have extended the processing of this product to all sites in the enhanced sonde network during MC3E. It is noted that the mean bias correction was derived for clear-sky conditions and is therefore not appropriate for cloudy sky conditions. We have not taken this into account for the MC3E sounding data set and so have applied the corrections for all-sky conditions. Figure 4 shows a set of twodimensional histograms of the difference in the dew point between the original soundings and the humidity-corrected soundings for all (panel a), daytime (panel b) and nighttime (panel c) soundings. These plots indicate that the corrections generally moisten the upper troposphere (above $8 \mathrm{~km}$ ) and dry the lower troposphere. Upper atmosphere moistening is more pronounced during the daytime while lower troposphere drying is more prevalent during the nighttime. 
Table 3. ARM defined min, max and delta data quality check limits. These limits are automatically applied to all MC3E soundings as part of the data ingest procedures. The delta check refers to the change between two adjacent data points. Data points that are outside of these limits are automatically flagged.

\begin{tabular}{llrrl}
\hline Variable Name & Units & Minimum & Maximum & Delta \\
\hline Pressure & $\mathrm{hPa}$ & 0.0 & 1100.0 & 10.0 \\
Dry bulb temperature & ${ }^{\circ} \mathrm{C}$ & -80.0 & 50 & 10.0 \\
Dew point temperature & ${ }^{\circ} \mathrm{C}$ & -110.0 & 50 & - \\
Wind speed & $\mathrm{m} \mathrm{s}^{-1}$ & 0.0 & 75.0 & - \\
Wind direction & $\mathrm{Deg}^{\circ}$ & 0.0 & 360.0 & - \\
Relative humidity with respect to liquid water & $\%$ & 0.0 & 100.0 & - \\
Eastward wind component & $\mathrm{m} \mathrm{s}^{-1}$ & -100.0 & 100.0 & - \\
Westward wind component & $\mathrm{m} \mathrm{s}^{-1}$ & -100.0 & 100.0 & - \\
Ascent rate & $\mathrm{m} \mathrm{s}^{-1}$ & -10.0 & 20.0 & 5.0 \\
\hline
\end{tabular}

Table 4. Data quality check failure rate. Summary of the percentage of observations for all sites outside of the data quality checked defined in Table 3.

\begin{tabular}{ll}
\hline Sounding Variable & \% outside limits \\
\hline All & 3.39 \\
Pressure & 0.001 \\
Temperature & 0.001 \\
Relative humidity/dew point temperature & 1.05 \\
Winds & 2.62 \\
Ascent rate & 0.007 \\
\hline
\end{tabular}

The SONDEADJUST value-added product (VAP) takes the sounding that has been corrected for known biases and then uses an independent retrieval of PWV to scale the radiosonde water vapor measurements (Turner et al., 2003; Cady-Pereira et al., 2008). During MC3E, there was a microwave radiometer (Turner et al., 2007; Gaustad et al., 2011) deployed at $\mathrm{C} 1$. We use the PWV observations from this MWR nearest the sonde launch time to scale the soundings launched from C1. Based on Global Climate Observing System (GCOS) Reference Upper-Air Network (GRUAN) RH uncertainly estimates, PWV uncertainty in RS92 sonde data is $\pm 2 \mathrm{~mm}$ (Yu et al., 2015); PWV uncertainty in MWR retrievals is $0.2-0.5 \mathrm{~mm}$ (Turner et al., 2007; Cadeddu et al., 2013). Under some circumstances, the scaling may act to reverse the M09 corrections however, this step is justified because (1) the M09 corrections were developed under clear-sky conditions and (2) RS92 accuracy also changes for batches manufactured at different times. To help mitigate both of these correction uncertainties, scaling to a reliable independent PWV source is useful. Figure 5 shows the diurnal variation in the PWV retrieved (hourly averaged around sonde launch time) from the MWR observations and from uncorrected and corrected radiosonde observations for the $\mathrm{C} 1$. The mean value over all $\mathrm{C} 1$ soundings shows that the PWV from the corrected radiosonde observations $(22.73 \mathrm{~mm})$ agrees very well with the MWR observations
(22.88 mm). The mean PWV bias between the MWR and corrected soundings is $0.127 \mathrm{~mm}$ compared to $0.396 \mathrm{~mm}$ between the MWR and uncorrected soundings. Clearly, the humidity corrections have improved the agreement between the soundings and MWR estimates of PWV by drying the nighttime soundings (4-5\%) and slightly moistening (2-3\%) the midday soundings.

Inherent in the notion of scaling the sonde humidity to a reliable independent measurement is the assumption that the radiosonde PWV should be the same as that observed by the independent sensor. While balloon drift and sampling scale mismatches may weaken this assumption, previous work by Turner et al. (2003) has shown that this extra constraint on radiosonde-observed water vapor profiles leads to improved modeling of clear-sky radiative fluxes. While the overall mean PWV from corrected soundings and the MWR agree extremely well, we use the ratio of the MWRRET PWV to the sonde PWV for each sounding as a constant scale factor for water vapor at all heights in the sounding in order to constrain shorter term fluctuations. Although no MWR observations are available for the extended radiosonde sites, there are GPS retrievals of PWV available from SuomiNet (http://www.suominet.ucar.edu) (Bevis et al., 1992; Ware et al., 2000) for the southern Great Plains region that were archived by the ARM External Data Center (http://www.arm.gov/xdc). Figure 5 also includes the diurnal variation of PWV retrieved from GPS observations at C1. Previous investigations have shown agreement between GPS, radiosonde and MWR observations of PWV to be within 1$2 \mathrm{~mm}$ (Emardson et al., 2000; Niell et al., 2001; Li et al., 2003; Garcia-Lorenz et al., 2009). Figure 5 shows that although the differences between GPS, MWR and corrected sounding PWV are within expected bounds, the GPS PWV is biased low compared to the MWR and corrected soundings. A similar dry bias in GPS PWV relative to soundings and MWR estimates of PWV was noted at several sites in a recent tropical field campaign (AMIE-ARM MJO Investigation Experiment) conducted over the Indian Ocean and west- 
(a)

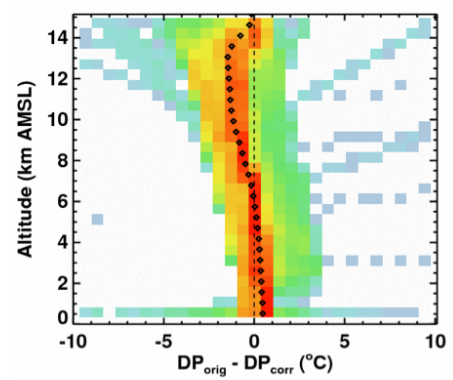

(b)

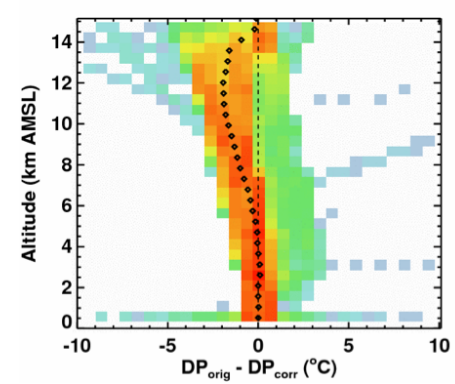

(c)

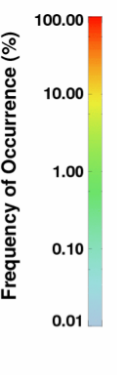

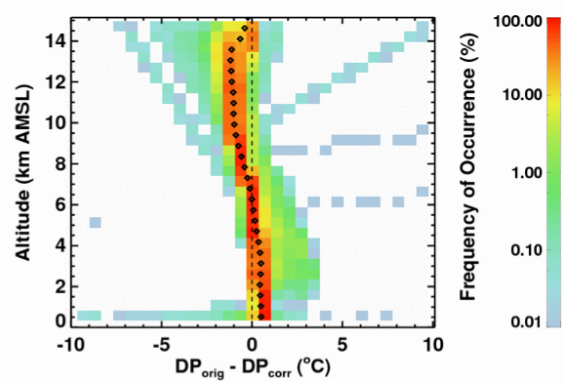

Figure 4. Two-dimensional histogram of humidity differences. Dew point (DP) difference between the original sounding and the humiditycorrected sounding for all soundings (a), daytime soundings (b) and nighttime soundings (c). The dotted black curve represents the median value at each height.

ern Pacific warm pool region (Ciesielski et al., 2014). Due to this dry bias in the GPS observations, estimates of GPS PWV were not used to scale the extended site radiosonde observations. Instead, the humidity-corrected, but un-scaled, radiosonde profiles provide our best estimate of actual moisture conditions.

\subsection{Higher-order value-added data products}

For $\mathrm{C} 1$, the corrected soundings are used as input into two higher-order products which both provide high-resolution profiles of atmospheric state for use in other derived products. The interpolated sonde (INTERPSONDE; Troyan, 2013) VAP begins with a simple linear interpolation (in time) of state variables observed by radiosondes to a $1 \mathrm{~min}$ time step. The water vapor profile is then scaled to the PWV retrieved from MWR observations and surface meteorological observations are attached. The main purpose of this VAP is to provide a quick estimate of atmospheric humidity in order to apply gaseous attenuation corrections to radar observations and a quick estimate of horizontal winds that can be used as a first guess in an iterative technique for dealiasing scanning radar Doppler velocity observations (Kollias et al., 2014). The INTERPSONDE VAP is further used as input to the Merged Sounding Product (MERGESONDE; Troyan, 2012a). The MERGESONDE VAP combines the state fields from INTERPSONDE with model output from the European Centre for Medium-range Weather Forecasting (ECMWF) via a weighted average dependent on the tempo- ral distance from an actual radiosonde observation such that the output product has no contribution from the ECMWF field at times when actual sonde measurements exist. The output of the MERGESONDE VAP is a $1 \mathrm{~min}$ time resolution description of atmospheric state (pressure, temperature, relative humidity, winds) at 266 altitude levels in the lowest $20 \mathrm{~km}$ of the atmosphere. Data from the INTERPSONDE and MERGESONDE VAP are available from the ARM data archive (http://www.archive.arm.gov).

\section{Analysis}

\subsection{Convective indices}

From the MC3E soundings, a number of convective indices and other quantities important for understanding the lifecycle of convective clouds are calculated. The amount of buoyant energy available for an adiabatically rising air parcel is known as convective available potential energy (CAPE). CAPE is calculated as the vertical sum of parcel buoyancy from the level of free convection (LFC) to the equilibrium level (EL) (Moncrieff and Miller, 1976). 

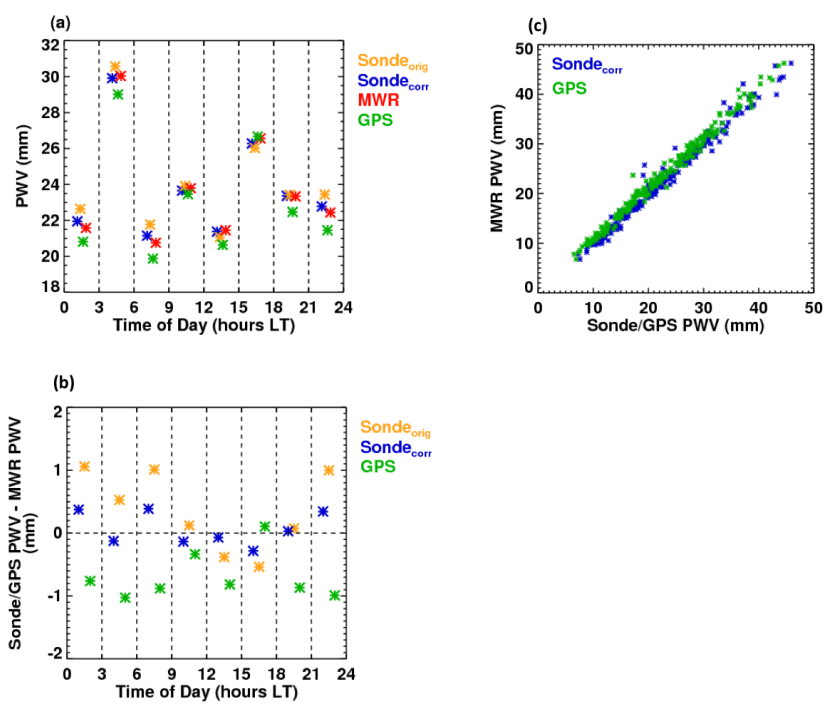

Figure 5. Diurnal variation of PWV at site C1. (a) Retrieved from an uncorrected sounding profile (yellow), a corrected sounding (blue), MWR observations (red) and GPS observations (green) averaged over all sondes in $3 \mathrm{~h}$ time windows; (b) absolute differences between retrieved PWV estimates; (c) scatterplot of retrieved PWV from corrected radiosonde profiles and GPS.

Here we calculate CAPE using the following equation:

$\mathrm{CAPE}=\sum_{\mathrm{LFC}}^{\mathrm{EL}}\left[\frac{\left(\theta_{\mathrm{p}}-\theta_{\mathrm{v}}\right)}{\theta_{\mathrm{v}}}\right] g \Delta z$,

where LFC is defined as the first level at which a rising parcel becomes positively buoyant, and EL is defined as the level (above the LFC) where the rising parcel changes from positive buoyancy to negative buoyancy. See Fig. 6 for a graphical representation of these levels. $\theta_{\mathrm{p}}[\mathrm{K}]$ is the virtual potential temperature of the rising parcel at height $z$ and is determined by assuming that a rising parcel experiences dry adiabatic ascent until it reaches the lifting condensation level (LCL), beyond which the parcel rises pseudo-adiabatically (i.e., condensed water is assumed to be instantaneously removed from the rising parcel). The LCL is determined following the convention of Bolton (1980) where the temperature of the LCL is determined from the following empirical equation (Eq. 15 from Bolton, 1980):

$T_{\mathrm{LCL}}=56.0+\left(1.0 /\left(1.0 / T_{\mathrm{d}}-56.0\right)+\ln \left(T / T_{\mathrm{d}}\right) / 800\right)$,

where $T_{\mathrm{d}}[\mathrm{K}]$ is the dew point temperature and $T[\mathrm{~K}]$ is the dry bulb temperature. The LCL is determined by finding the height at which the temperature of a parcel rising dry-adiabatically is equal to its original $T_{\mathrm{LCL}} \cdot \theta_{\mathrm{v}}[\mathrm{K}]$ is the virtual potential temperature of the environment at height $z$, $g\left(\mathrm{~m} \mathrm{~s}^{-2}\right)$ is the acceleration due to gravity and $\Delta z$ is the change in height from level $i-1$ to level $i$ (Moncrieff and Miller, 1976). The calculated CAPE value can then be interpreted as a control on the upper limit of the possible updraft

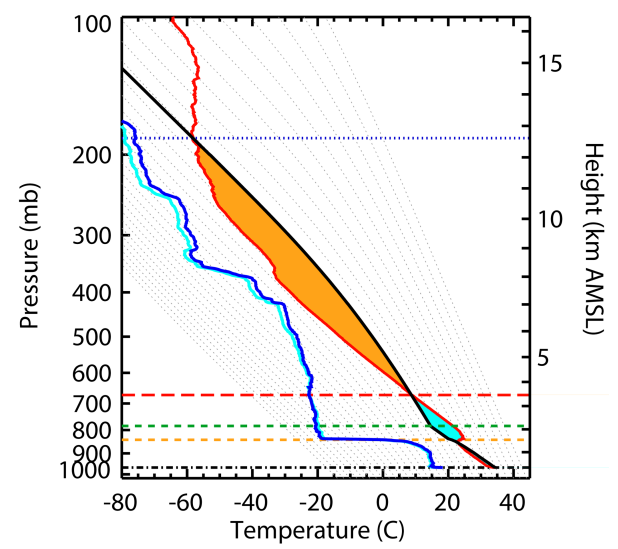

Figure 6. Graphical representation of convective indices. Central Facility radiosonde profile for 11 May 2011 02:34 UTC graphically illustrating the convective indices of CAPE (orange shading) and CIN (cyan shading) and relevant buoyancy levels including the lifting condensation level (LCL, green dashed), level of free convection (LFC, red dashed) and equilibrium level (blue dotted). The environmental virtual temperature profile is shown by the solid red line, adiabatic virtual parcel temperature is shown by the solid black line, the observed dew point temperature profile is shown with the dark blue line and the $\mathrm{RH}$-corrected dew point temperature profile is shown with the cyan line.

velocity during convective storm initiation and growth, although this upper limit is never realized due to the impacts of entrainment, vertical pressure gradients and water loading.

The magnitude of CAPE is strongly dependent on the environmental density profile (i.e., temperature and humidity) and the choice of the level of free convection and equilibrium level through the initial parcel characteristics. The definition of initial parcel characteristics has such a profound impact on the magnitude of CAPE that different "flavors" of CAPE have been defined to specify this description. Here, we calculate CAPE by defining the initial parcel characteristics in two ways. We compute $\mathrm{CAPE}_{\mathrm{SB}}$ using the lowest sounding observation (SBCAPE from Bunkers et al., 2002), and we compute $\mathrm{CAPE}_{\mathrm{MU}}$ using the level of maximum virtual temperature in the lowest kilometer above ground level of the sounding (similar to the CAPE computed with the most unstable parcel in the lower atmosphere, MUCAPE, from Bukners et al., 2002). $\mathrm{CAPE}_{\mathrm{SB}}$ is generally most relevant for situations wherein predominantly surface-based convection is of interest. CAPE $\mathrm{MU}_{\mathrm{MU}}$ provides a maximum estimate of CAPE and is most often relevant in cases of elevated convection (Rochette et al., 1999).

As illustrated in Fig. 6, there is often an area of negative buoyancy below the level of free convection that is known as convective inhibition (CIN). CIN can be thought of as a measure of the work that an air parcel must do in order to reach the LFC where it will finally become positively buoyant. Mathematically, CIN can be expressed as such: 


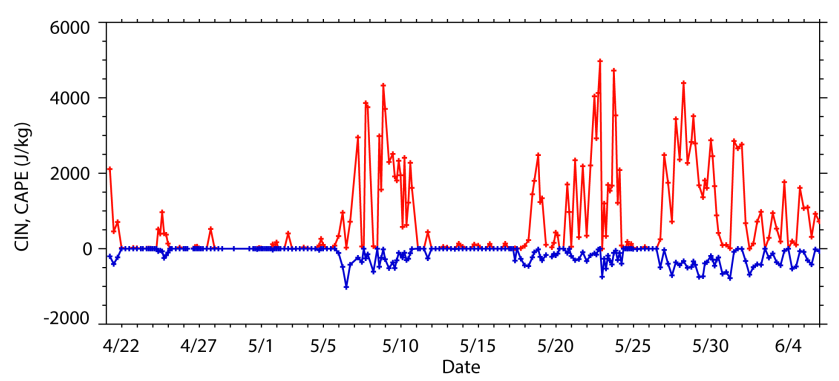

Figure 7. Time series of $\mathrm{CAPE}_{\mathrm{MU}}$ (red) and $\mathrm{CIN}_{\mathrm{MU}}$ (blue) at the ARM C1 over the course of the MC3E field campaign, using corrected sounding humidity. Three distinct active convective periods are easily identifiable (6-11 May, 18-23 May and 26 May-6 June) with high CAPE and low CIN values.

$\mathrm{CIN}=\sum_{\mathrm{SFC}}^{\mathrm{LFC}}\left[\frac{\left(\theta_{\mathrm{p}}-\theta_{\mathrm{v}}\right)}{\theta_{\mathrm{v}}}\right] g \Delta z$

where SFC is the surface level (more details on this later) and all other variables are defined in the same manner as Eq. (1). Figure 7 shows a time series of $\mathrm{CAPE}_{\mathrm{MU}}$ and $\mathrm{CIN}_{\mathrm{MU}}$ at the SGP C1 using uncorrected humidity soundings over the entire length of the MC3E field campaign.

\subsection{Sensitivity to measurement uncertainties}

The determination of the LCL, LFC, EL, CAPE and CIN are sensitive to the details of the profiles of temperature and humidity. Uncertainties in the calculation of these quantities are a function of the uncertainties and biases (e.g., the relative humidity biases discussed in Sect. 3.1) in the observed thermodynamic profile and the assumptions used in the algorithm for the calculation of each quantity. Here, we will investigate the uncertainties in the calculated CAPE/CIN due to each of these causes.

\subsubsection{Differences due to humidity corrections}

This subsection presents an analysis of differences found in computed convective indices based on correction of the humidity profile as defined in Sect. 3.1. For all comparisons herein, computations are made using the surface parcel defined according to the calculation of $\mathrm{CAPE}_{\mathrm{MU}}$.

Figure 8 shows scatterplots, for MC3E soundings at all six sites, for three convective levels: (a) LCL, (b) LFC and (c) EL, calculated with and without the humidity corrections. Each of these convective levels, important for the calculation of higher-order convective indices (e.g., CAPE and CIN), shows relatively small sensitivity to the humidity corrections.

Although $86 \%$ of the soundings show a difference in the LCL of greater than $1 \%$, only $3 \%$ show a difference greater than $10 \%$. During nighttime hours (00:0012:00 UTC), when we see more drying in the boundary layer,
$96 \%$ of the soundings show a difference in LCL of greater than $1 \%$, while still only $3 \%$ show a difference greater than $10 \%$. During the daytime hours (12:00-24:00 UTC), significantly fewer soundings $(76 \%)$ show a difference of more than $1 \%$, while $3.6 \%$ show a difference greater than $10 \%$, similar to evening. A comparison of the mean LCL over all MC3E soundings shows the LCL with humidity corrections applied to be $39 \mathrm{~m}$ higher than the LCL for the original soundings with a standard deviation of the difference between the two LCL estimates of $86 \mathrm{~m}$. Furthermore, the relative humidity correction generally results in higher LCLs during both day and night, with resultant LCLs 10 and $68 \mathrm{~m}$ higher on average, with standard deviations of 54 and $101 \mathrm{~m}$, respectively.

Turning to the LFCs, $48 \%$ of the soundings exhibit a difference of at least $1 \%$ in the LFC, and $5 \%$ exhibit a difference of more than $50 \%$. During daytime only hours (12:00 24:00 UTC) or nighttime only hours (00:00-12:00 UTC), the statistics are similar with $48.6 \%$ of daytime and $47.4 \%$ of nighttime soundings showing differences of at least $1 \%$, and $6.2 \%$ of daytime and $4.3 \%$ of nighttime soundings showing a difference of more than $50 \%$. The mean difference in LFC over all MC3E soundings is only $6 \mathrm{~m}$ with a standard deviation of $854 \mathrm{~m}$, however the humidity correction on daytime soundings results in a positive mean difference (original less humidity-corrected) of $27 \mathrm{~m}$ (with a standard deviation of $989 \mathrm{~m}$ ), while for nighttime soundings it results in a negative mean difference of $17 \mathrm{~m}$ (with a standard deviation of $686 \mathrm{~m}$ ), indicating that the relative humidity correction generally results in lower LFCs during the day and higher LFCs during the night.

The ELs show differences of greater than $1 \%$ for only $29.4 \%$ of the soundings with $5.9 \%$ having differences larger than $10 \%$. Daytime and nighttime soundings show similar statistics with 28.4 and $30.5 \%$ exhibiting differences greater than $1 \%$, respectively, and $5.9 \%$ of both showing differences of at least $10 \%$. The mean difference in EL over all MC3E soundings is $126 \mathrm{~m}$ (original less humidity-corrected), with a standard deviation of $729 \mathrm{~m}$. However, during the daytime hours, the ELs of corrected soundings are $42 \mathrm{~m}$ (standard deviation of $744 \mathrm{~m}$ ) lower than uncorrected, while during nighttime hours, as defined here, the difference is even greater, with corrected soundings having an EL $214 \mathrm{~m}$ (standard deviation of $703 \mathrm{~m}$ ) lower on average. This follows the fact that nighttime-corrected soundings tend to have generally higher LCLs than uncorrected soundings, and more so than daytime soundings. In general, soundings that show a difference in LCL also show differences for LFC and EL.

These differences in convective levels in the atmosphere have corresponding impacts on the convective indices they are used to calculate. Figure 9 shows a scatterplot of the (a) CAPE and (b) CIN calculated without the humidity corrections versus the same quantities calculated using the corrected humidity profiles. Daytime soundings (12:0024:00 UTC) are indicated with red markers while nighttime 
(a)

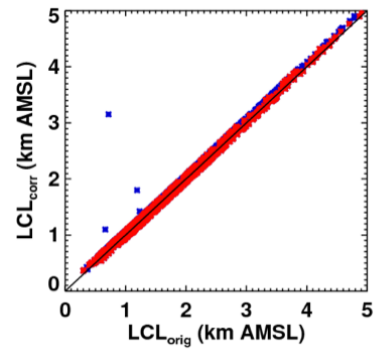

(c)

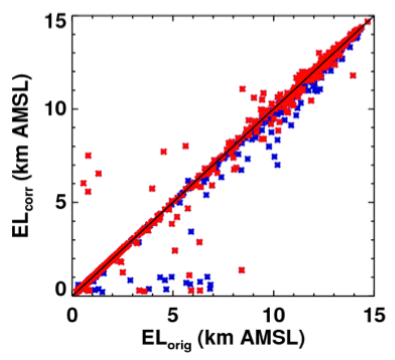

(b)

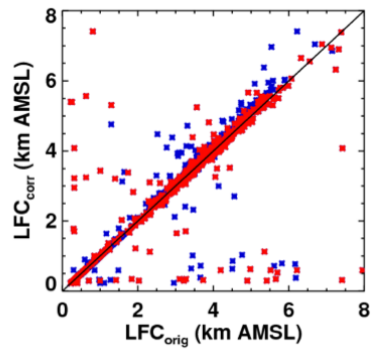

(a)

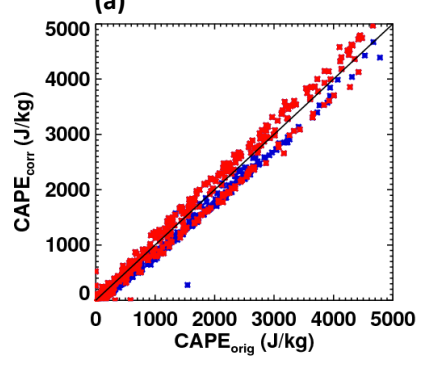

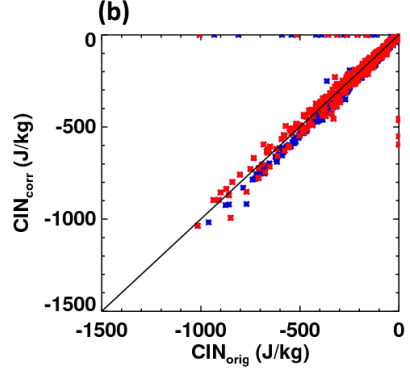

Figure 9. Scatterplots of convective indices comparing original (orig) and humidity-corrected (corr) soundings for (a) CAPE and (b) CIN. Daytime soundings (12:00-24:00 UTC) are indicated with red markers while nighttime soundings are blue.

impact on the calculation of CAPE/CIN from corrections to the measured profile of humidity.

\subsubsection{Differences due to surface parcel characteristics}

Figure 8. Scatterplots of convective levels comparing original (orig) and humidity-corrected (corr) soundings for (a) LCL, (b) LFC and (c) EL. Daytime soundings (12:00-24:00 UTC) are indicated with red markers while nighttime soundings are blue. Convective levels are computed using the level of maximum virtual temperature in the lowest kilometer above ground level of the sounding.

soundings are blue. In total $42.1 \%(45.2 \%)$ of the CAPE (CIN) values agree to within $1 \%$. A closer look at the cases with greater differences shows that $12.2 \%(7 \%)$ of the CAPE (CIN) values disagree by more than $50 \%$. Because there is a correlation between the relative magnitude of the differences and the absolute value of the CAPE/CIN, we also present simple statistical measures of the absolute differences in CAPE/CIN for several different ranges, categorized by the magnitude of the CAPE/CIN value of the corrected soundings. For soundings with CAPE less than $500 \mathrm{~J} \mathrm{~kg}^{-1}$, the mean difference (original less humidity-corrected) in CAPE is $14 \mathrm{~J} \mathrm{~kg}^{-1}$ with a standard deviation of $63 \mathrm{~J} \mathrm{~kg}^{-1}$, while for CAPE values between 500 and $2000 \mathrm{~J} \mathrm{~kg}^{-1}$ the mean difference is $105 \mathrm{~J} \mathrm{~kg}^{-1}$ with a standard deviation of $164 \mathrm{~J} \mathrm{~kg}^{-1}$ and finally for CAPE values greater than $2000 \mathrm{~J} \mathrm{~kg}^{-1}$ the mean difference is $22 \mathrm{~J} \mathrm{~kg}^{-1}$ with a standard deviation of $240 \mathrm{~J} \mathrm{~kg}^{-1}$. For soundings with CIN values greater than $-100 \mathrm{~J} \mathrm{~kg}^{-1}$ the mean difference between CIN calculated from the original soundings and those with humidity corrections applied is $-9.5 \mathrm{~J} \mathrm{~kg}^{-1}$ with a standard deviation of $75 \mathrm{~J} \mathrm{~kg}^{-1}$. For soundings with CIN between -100 and $-500 \mathrm{~J} \mathrm{~kg}^{-1}$ the mean of the differences is $17 \mathrm{~J} \mathrm{~kg}^{-1}$ with a standard deviation of $40.5 \mathrm{~J} \mathrm{~kg}^{-1}$. Finally, soundings with CIN less than $-500 \mathrm{~J} \mathrm{~kg}^{-1}$ show mean differences of $39 \mathrm{~J} \mathrm{~kg}^{-1}$ with a standard deviation of $84 \mathrm{~J} \mathrm{~kg}^{-1}$. These results indicate that for many soundings there is a significant

This subsection presents an analysis of the sensitivity of convective index computation to surface parcel definition as introduced in Sect. 4.1. For all comparisons that follow, computations are made using humidity-corrected soundings for all six MC3E sites.

Figure 10 shows a comparison of the (a) LCL, (b) LFC and (c) EL for the two separate definitions of the surface parcel: (1) lowest sounding observation (SB) and (2) level of maximum virtual temperature in the lowest kilometer (MU). The scatterplots show that each of these convective levels exhibits strong sensitivity to the definition of the surface parcel characteristics. It should be noted that for most of the cases where the LCL, LFC or EL agree to within 1\%, it was found that the surface observation was also the level of maximum virtual temperature in the lowest kilometer. For the LCL, $56 \%$ of the soundings show differences greater than $1 \%$, while $32 \%$ show differences greater than $50 \%$. The mean difference in LCL is $510 \mathrm{~m}$ (maximum virtual temperature less the lowest sounding level) with a standard deviation of $906 \mathrm{~m}$ (i.e., when the surface parcel is defined using the lowest sounding level, the LCL tends to be lower). The LFC shows a similar pattern of differences between the surface parcel representations. In this case, $55.7 \%$ of the soundings show a difference greater than $1 \%$ for the two surface parcel representations while $32.9 \%$ of the soundings show differences larger than $50 \%$. The mean difference in LFC is $430 \mathrm{~m}$ with a standard deviation of $1600 \mathrm{~m}$. Similar to the LCL and LFC, the EL scatterplot also shows differences of greater than $1 \%$ for $52.7 \%$ of the MC3E soundings with differences larger than $50 \%$ in $32.5 \%$ of the soundings. The mean difference in EL is $1485 \mathrm{~m}$ with a standard deviation of $3992 \mathrm{~m}$.

These differences in the LCL, LFC and EL translate into differences in the CAPE and CIN. Figure 11 shows scatterplots of the (a) CAPE and (b) CIN calculated using the 
(a)

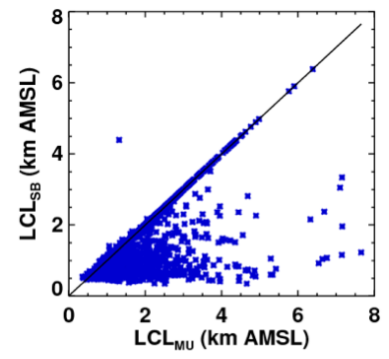

(c)

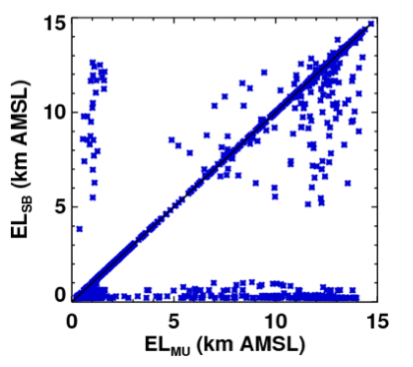

(b)

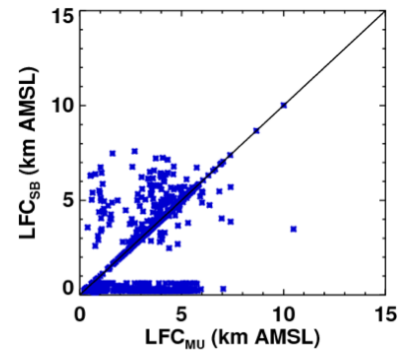

Figure 10. Scatterplots of convective levels, computed using RHcorrected soundings, comparing estimates for surface parcel characteristics defined by the level with the maximum virtual temperature in the lowest kilometer (MU) and the lowest level in the sounding (SB) for (a) LCL, (b) LFC and (c) EL.

level of maximum virtual temperature in the lowest $1 \mathrm{~km}$ to define the surface parcel characteristics versus calculations using the lowest level observation from each sounding. For CAPE (CIN), $37.5 \%(34.7 \%)$ of the soundings show differences greater than $1 \%$, while $32.9 \%(29.4 \%)$ of the cases show differences greater than $50 \%$. That is, when there is a difference in the calculation of CAPE or CIN due to the definition of the surface parcel, it is generally a significant one. Also, recall that for many of the cases where there was no impact on the estimation of LCL, LFC or EL, the two representations of surface parcel characteristics were identical (and therefore by definition would result in no difference in any of the quantities investigated).

Again, we will consider the differences in terms of categories to account for the correlation between the relative magnitude of differences and the absolute value of the CAPE/CIN, binning here by the magnitude of the CAPE/CIN value computed using the maximum virtual temperature in the lowest $1 \mathrm{~km}$. For soundings with CAPE less than $500 \mathrm{~J} \mathrm{~kg}^{-1}$ (using the corrected $\mathrm{RH}$ ) the mean difference in CAPE between the two descriptions of surface parcel characteristics is $-24 \mathrm{~J} \mathrm{~kg}^{-1}$ with a standard deviation of $241 \mathrm{~J} \mathrm{~kg}^{-1}$, while for CAPE values between 500 and $2000 \mathrm{~J} \mathrm{~kg}^{-1}$ the mean difference is $488 \mathrm{~J} \mathrm{~kg}^{-1}$ with a standard deviation of $646 \mathrm{~J} \mathrm{~kg}^{-1}$ and finally for CAPE values greater than $2000 \mathrm{~J} \mathrm{~kg}^{-1}$ the mean difference is $824 \mathrm{~J} \mathrm{~kg}^{-1}$ with a standard deviation of $1194 \mathrm{~J} \mathrm{~kg}^{-1}$. For soundings
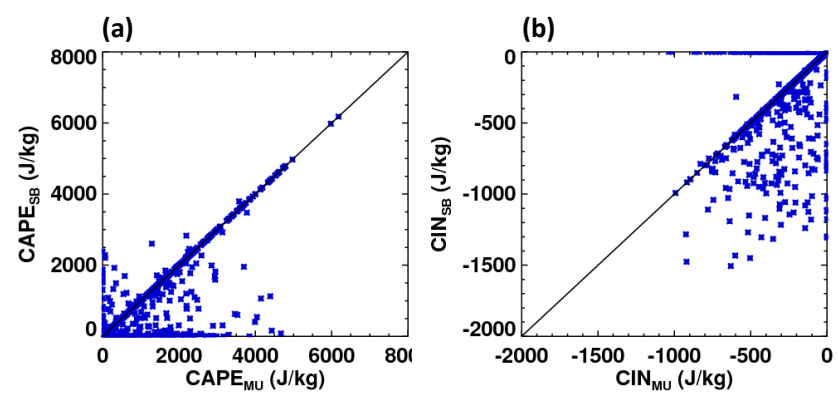

Figure 11. Scatterplots of convective indices, computed using RHcorrected soundings, comparing estimates for surface parcel characteristics defined by the level with the maximum virtual temperature in the lowest kilometer (MU) and the lowest level in the sounding (SB) for (a) CAPE and (b) CIN.

with CIN values greater than $-100 \mathrm{~J} \mathrm{~kg}^{-1}$ the mean difference between CIN is $34 \mathrm{~J} \mathrm{~kg}^{-1}$ (maximum virtual temperature in lowest kilometer representation minus lowest sounding observation representation) with a standard deviation of $171 \mathrm{~J} \mathrm{~kg}^{-1}$. For soundings with CIN between -100 and $-500 \mathrm{~J} \mathrm{~kg}^{-1}$ the mean of the differences is $15.6 \mathrm{~J} \mathrm{~kg}^{-1}$ with a standard deviation of $284 \mathrm{~J} \mathrm{~kg}^{-1}$. Finally, soundings with CIN less than $-500 \mathrm{~J} \mathrm{~kg}^{-1}$ show mean differences of $-92 \mathrm{~J} \mathrm{~kg}^{-1}$ with a standard deviation of $421 \mathrm{~J} \mathrm{~kg}^{-1}$. These results indicate that for many soundings, there is a significant impact on the calculation of CAPE and CIN due to the representation of the surface parcel characteristics and this sensitivity is larger than that due to the sounding humidity biases found in this study.

\subsubsection{Impacts on large-scale forcing}

The major justification for the deployment of the sounding array during $\mathrm{MC} 3 \mathrm{E}$ is for the derivation of a largescale model forcing data set to drive single-column, cloudresolving and land-surface model simulations. Towards this goal, Xie et al. (2014) use the constrained variational analysis approach of Zhang and Lin (1997) in order to derive the large-scale vertical velocity and advective tendencies of temperature and moisture over the MC3E domain. This technique uses a combination of sounding network observations, ARM extended facility observations, radar-derived surface precipitation and top-of-atmosphere radiative flux observations as constraints to adjust the sounding-observed atmospheric state variables in order to conserve column-integrated mass, moisture and static energy such that the resulting forcing data set is dynamically and thermodynamically consistent. Here, we investigate the impact of the sounding quality control and humidity corrections on the derived large-scale vertical velocity. Figure 12 shows a time series of the largescale vertical velocity derived using the quality-controlled, humidity-corrected soundings and the difference compared to the vertical velocity derived using the raw sounding ob- 

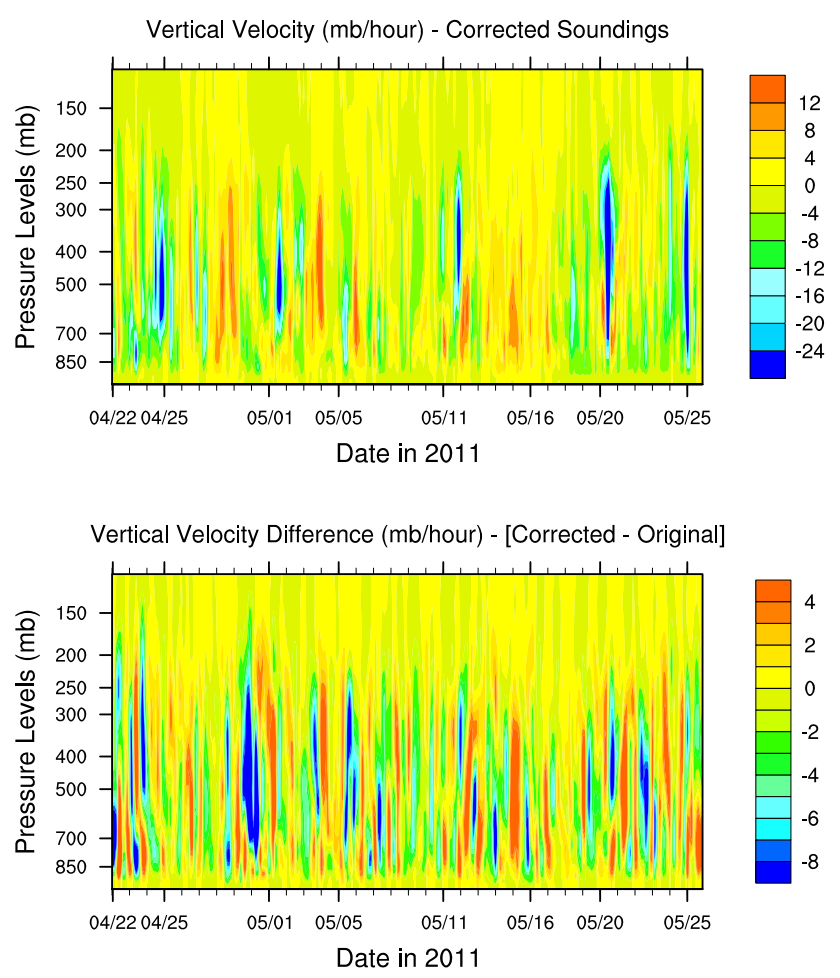

Figure 12. Comparison of large-scale forcing data set for original and corrected soundings. Derived large-scale vertical velocity using quality-controlled, humidity-corrected radiosonde profiles (top) and the difference (corrected-original) between the derived large-scale forcing using the corrected soundings and the original soundings. Please note that dates are given in month/day format.

servations. The results show differences in the derived vertical velocity ranging from +5 to $-9 \mathrm{hPa} \mathrm{h}^{-1}$. The magnitudes of these differences are significant compared to the derived vertical velocity ranging from +13 to $-25 \mathrm{hPah}^{-1}$. These differences could lead to significant differences in the simulation of convective clouds and illustrate the importance of accurate measurements of atmospheric state profiles for input to large-scale forcing estimates.

\section{Summary and conclusions}

An important component of the MC3E field campaign was the collection of an extensive sounding data set that included observations from six sites covering and area of $300 \times 300 \mathrm{~km}$.

A total of 1362 soundings were launched from this array over the course of the 6-week campaign. Routine ARM processing of the sounding data set included a set of automatic quality checks on the magnitude and variability of the observations. Known humidity biases were corrected using the empirical algorithms defined by Milosevich et al. (2009) and when available compared to independent observations of PWV. At the central ARM facility, where reliable inde- pendent measurements of PWV were available, the humidity corrections were shown to improve the agreement between the sonde and MWR PWV observations with a mean PWV difference of $0.15 \mathrm{~mm}$ (or $0.7 \%$ ). These corrections along with rigorous quality control of the soundings have resulted in a high-quality data set suitable for many research applications including the derivation of a model forcing data set (Xie et al., 2014).

An analysis of the impact of the corrections for known humidity biases and assumptions regarding surface parcel definitions show that both have significant impacts on the determination of convective levels and indices for many soundings. The impact of assumptions about surface parcel characteristics generally has a greater impact on these levels and indices than the humidity corrections applied in this study. Further, an investigation of the impacts of the sounding humidity corrections and quality control on the derived largescale forcing fields indicate significant influences on the calculated large-scale vertical velocity. These differences would have important implications for model simulation of convective events.

The MC3E sounding data set (Jensen and Toto, 2014) is available from the ARM archive (www.archive.arm.gov). The raw sounding data for the Central Facility, C1, is a regular ARM data stream (sgpsondewnpn*) and can be found using the ARM archive tools. The boundary facility (S1, S2, S3, S4 and S5) humidity-corrected soundings are available from the MC3E IOP archive (http://iop.archive.arm.gov/arm-iop/ 2011/sgp/mc3e).

Acknowledgements. The authors wish to thank the program managers of the DOE ARM program, Wanda Ferrell, and the NASA GPM program, Ramash Karkar and Arthur Hou, for their support of the MC3E field campaign. We also wish to acknowledge the scientists and staff that participated in the deployment stage of the MC3E field campaign, particularly those who contributed to the radiosonde activities including Mike Bobbitt, Phil Cardwell, Debi Chaney, Marilyn Dowell, Mary Green, Shawn Muegge, Sandra Schovanec, Mike Shaffer, Lynda Theilen, James Cunningham, James Rowland, Robin Moore, Leah Nelson, Jim Callison, Cris Alvarez, Tony Newman, Seth Galemore, Parker Huitt, Kenneth Crick, Donald Cook, Clydie Prince, Tracy Messer, John Duncan, Cameron Summers, Raymond Cline, Bruce Sewell, Tim Ahlstrom, Daniel Harnos, Kim Reed, Joseph Wegman, Melissa Peterson, Tristan Hall, Peter Patina, Matthew Grey, Matthew Dawson, Robert Seigel, Tiffany Meyer, Elizabeth Thompson, Cort Sholten. Participation by BNL scientists has been supported by the Office of Biological and Environmental Research of the US Department of Energy as part of the Atmospheric Radiation Measurement program, the Atmospheric Systems Research Program and the Earth System Modeling Program. Paul Ciesielski acknowledges his support from the NASA PPM grant NNX13AF74G.

Edited by: J. Joiner 


\section{References}

Ackerman, T. P. and Stokes, G. M.: The Atmospheric Radiation Measurement Program, Phys. Today, 56, 38-45, 2003.

Bevis, M., Businger, S., Herring, T. A., Rocken, C., Anthes, R. A., and Ware, R. H.: GPS Meteorology: Remote sensing of atmospheric water vapor using the global positioning system, J. Geophys. Res., 97, 787-801, 1992.

Bolton, D.: Computation of equivalent potential temperature, Mon. Weather Rev., 108, 1046-1053, 1980.

Bunkers, M. J., Klimowski, B. A., and Zeitler, J. W.: The importance of parcel choice and the measure of vertical wind shear in evaluating the convective environment, Preprints, 21st Conf. Severe Local Storms, San Antonio, American Meteorological Society, J117-J120, 11-16 August 2002.

Cadeddu, M. P., Liljegren, J. C., and Turner, D. D.: The Atmospheric radiation measurement (ARM) program network of microwave radiometers: instrumentation, data, and retrievals, Atmos. Meas. Tech., 6, 2359-2372, doi:10.5194/amt-6-2359-2013, 2013.

Cady-Pereira, M. W., Shephard, D. D., Turner, E. J., Mlawer, S. A., Clough, T., and Wagner, J.: Improved Daytime ColumnIntegrated Precipitable Water Vapor from Vaisala Radiosonde Humidity Sensors, J. Atmos. Ocean. Tech., 25, 873-883, doi:10.1175/2007JTECHA1027.1, 2008.

Ciesielski, P. E, Yu, H., Johnson, R. H., Yoneyama, K., Katsumata, M., Long, C. N., Wang, J., Loehrer, S. M., Young, K., Williams, S. F., Brown, W., Braun, J., and Van Hove, T.: Quality controlled upper-air sounding dataset for DYNAMO/CINDY/AMIE: development and corrections, J. Atmos. Ocean. Tech., 31, 741-764, 2014

Dong, X., Mace, G. G., Minnis, P., Smith, W. L., Poellet, M., Marchand, R. T., and Rapp, A. D.: Comparison of stratus cloud properties defined from surface, GOES, and aircraft data during the March 2000 ARM Cloud IOP, J. Atmos. Sci., 59, 3265-3284, 2002.

Emardson, T. R., Johansson, J., and Elgered, G.: The systematics behavior of water vapor estimates using four years's of GPS observations, IEEE T. Geosci. Remote, 38, 324-329, 2000.

Garcia-Lorenzo, B., Castro-Almazan, J. A., Eff-Darwich, A., Munoz-Tunon, C., Pinilla-Alonso, N., Rodrigues-Espinosa, J. M., and Romero, I.: Precipitable water vapour content above the Roque de los Muchachos observatory from GPS estimations, Proc. SPIE 7475, Remote Sensing of Clouds and the Atmosphere XIV, 74751H, 29 September 2009, doi:10.1117/12.830235, 2009.

Gaustad, K. L., Turner, D. D., and McFarlane, S. A.: MWRRET Value-Added Product: The Retrieval of Liquid Water Path and Precipitable Water Vapor from Microwave Radiometer (MWR) Data Sets. DOE/SC-ARM-TR-081.2, 5 pp., 2011.

Ghan, S. J., Randall, D. A., Xu, K.-M., Cederwall, R., Cripe, D., Hack, J., Icobellis, S., Klein, S., Krueger, K., Lohmann, U., Pedretti, J., Robock, A., Rotsayn, L., Somerville, R., Stechikov, G., Sud, Y., Walker, G., Xie, S. C., Yio, J., and Zhang, M. H.: An intercomparison of single column model simulations of summertime midlatitude continental convection, J. Geophys. Res., 105, 2091-2124, 2000.

Holdridge, D. J., Prell, J. A., Ritsche, M. T., and Coulter, R.: Balloon-Borne Sounding System (SONDE) Handbook. DOE/SC-ARM-TR-029, U.S. Department of Energy, Office of Science, Office of Biological and Environmental Research, 28 pp., 2011.

Hou, A. Y., Kakar, R. K., Neeck, S., Azarbarzin, A. A., Kummerow, C. D., Kojima, M., Oki, R., Nakamura, K., and Iguchi, T.: The Global Precipitation Measurement (GPM) Mission, B. Am. Meteorol. Soc., 95, 701-722, doi:10.1175/BAMS-D-1300164.1, 2014.

Jensen, M. P. and Toto, T.: Humidity-corrected sounding observations (SONDEADJUST). April-June 2011, $36.695^{\circ} \mathrm{N}$, $97.485^{\circ} \mathrm{W} ; \quad 37.7^{\circ} \mathrm{N}, \quad 98.75^{\circ} \mathrm{W} ; \quad 37.674^{\circ} \mathrm{N}, \quad 95.488^{\circ} \mathrm{W}$; $36.071^{\circ} \mathrm{N}, \quad 99.204^{\circ} \mathrm{W} ; \quad 35.678^{\circ} \mathrm{N}, \quad 95.586^{\circ} \mathrm{W} ; 34.985^{\circ} \mathrm{N}$, $97.522^{\circ} \mathrm{W}$ : Southern Great Plains Sites C1, S1, S2, S3, S4, S5. Atmospheric Radiation Measurement (ARM) Climate Research Facility Data Archive: Oak Ridge, TN, USA, doi:10.5439/1164928, 2014.

Jensen, M. P., Kollias, P., Del Genio, A. D., Giangrande, S. E., Orr, B., Petersen, W. A., Schwaller, M. R., Hou, A. Y., Rutledge, S. A., Heymsfield, G., Heymsfield, A., and Zipser, E.: MidLatitude Continental Convective Cloud Experiment (MC3E) Science and Implementation Plan. DOE/ARM Technical Report number DOE/SC-ARM/10-004, U.S. Department of Energy, Office of Science, Office of Biological and Environmental Research, 2010.

Johnson, R. H.: Partitioning tropical heat and moisture budgets into cumulus and mesoscale components: Implications for cumulus parameterization, Mon. Weather Rev., 112, 1590-1601, 1984.

Johnson, R. H. and Ciesielski, P. E.: Structure and properties of Madden-Julian Oscillations deduced from DYNAMO sounding arrays, J. Atmos. Sci., 70, 3157-3179, 2013.

Klein, S. A. and Del Genio, A. D.: ARM's support for GCM improvement: A white paper, U.S. Department of Energy. DOE/SCARM/P-06-012, U.S. Department of Energy, Office of Science, Office of Biological and Environmental Research, 2006.

Kollias, P., Jo, I., Borque, P., Tatarevic, A., Lamer, K., Bharadwaj, N., Widener, K., Johnson, K. L., and Clothiaux, E. E.: Scanning ARM cloud radars. Part II: Data quality control and processing, J. Atmos. Ocean. Tech., 31, 583-598, doi:10.1175/JTECH-D-13$00045.1,2014$.

Li, Z., Muller, J.-P., and Cross, P.: Comparison of precipitable water vapor derived from radiosonde, GPS, and Moderate-Resolution Imaging Spectroradiometer measurements, J. Geophys. Res., 108, 4651, doi:10.1029/2003JD003372, 2003.

Mather, J. H. and Voyles, J. W.: The ARM Climate Research Facility: A Review of Structure and Capabilities, B. Am. Meteorol. Soc.., 94, 377-392, 2013.

Miller, M. A.: SGP Cloud and Land Surface Interaction Campaign (CLASIC): Science and Implementation Plan. U.S. Department of Energy. DOE/SC-ARM-0703, U.S. Department of Energy, Office of Science, Office of Biological and Environmental Research, 2007.

Miloshevich, L. M., Paukkunen, A., Vömel, H., and Oltmans, S. J.: Development and validation of a time-lag correction for Vaisala radiosonde humidity measurements, J. Atmos. Ocean. Tech., 21, 1305-1327, 2004.

Miloshevich, L. M, Vomel, H., Whiteman, D. N., and Leblanc, T.: Accuracy assessment and correction of Viasala RS92 radiosonde water vapor measurements, J. Geophys. Res., 114, D11303, doi:10.1029/2008JD011565, 2009. 
Moncrieff, M. W. and Miller, M. J.: The dynamics and simulation of tropical cumulonimbus and squall lines, Q. J. Roy. Meteor. Soc., 102, 373-394, 1976.

Morris, V. R.: Microwave Radiometer (MWR) handbook, DOE/SCARM-TR-016, U.S. Department of Energy, Office of Science, Office of Biological and Environmental Research, 20 pp., 2006.

Niell, A. E., Coster, A. J., Solheim, F. S., Mendes, V. B., Toor, P. C., Langley, R. B., and Upham, C. A.: Comparison of Measurements of Atmospheric Wet Delay by Radiosonde, Water Vapor Radiometer, GPS, and VLBI, J. Atmos. Ocean. Tech., 18, 830-850, doi:10.1175/15200426(2001)018<0830:COMOAW>2.0.CO;2, 2001.

Ritsche, M. T. and Prell, J.: Temperature, Humidity, Winds And Pressure System (THWAPS) handbook. DOE/ARM-TR-030, U.S. Department of Energy, Office of Science, Office of Biological and Environmental Research, 11 pp., 2011.

Rochette, S. M., Moore, J. T., and Market, P. S.: The importance of parcel choice in elevated CAPE computations, Natl. Wea. Dig., 23, 20-32, 1999.

Stokes, G. M. and Schwartz, S. E.: The Atmospheric Radiation Measurement (ARM) Program: Programmatic background and design of the cloud and radiation test bed, B. Am. Meteorol. Soc., 75, 1201-1221, 1994.

Troyan, D.: Merged Sounding Value-Added Product Technical Report. DOE/SC-ARM-TR-087, U.S. Department of Energy, Office of Science, Office of Biological and Environmental Research, 13 pp., 2012a.

Troyan, D.: Sonde Adjust Value-Added Product Technical Report. DOE/SC-ARM-TR-102. U.S. Department of Energy, Office of Science, Office of Biological and Environmental Research, 19 pp., $2012 b$.

Troyan, D.: Interpolated Sounding Value-Added Product Technical Report. DOE/SC-ARM/TR-124. U.S. Department of Energy, Office of Science, Office of Biological and Environmental Research, 13 pp., 2013.

Turner, D. D., Lescht, B. M., Clough, S. A., Liljigren, J. C., Revercomb, H. E., and Tobin, D. C.: Dry bias and variability in Vaisala $\mathrm{RS} 80-\mathrm{H}$ radiosondes: The ARM experience, J. Atmos. Ocean. Tech., 20, 117-132, doi:10.1175/15200426(2003)030<0117:DBAVIV>2.0CO;2, 2003.

Turner, D. D., Clough, S. A., Liljegren, J. C., Clothiaux, E. E., Cady-Pereira, K., and Gaustad, K. L.: Retrieving liquid water path and precipitable water vapor from Atmospheric Radiation measurement (ARM) microwave radiometers, IEEE T. Geosci. Remote, 45, 3680-3690, doi:10.1109/TGRS.2007.903703, 2007.
Ware, R. H., Fulker, D. W., Stein, S. A., Anderson, D. N., Avery, S. K., Clark, R. D., Groegemeir, K. K., Kuettner, J. P., Minster, J. B., and Sorooshian, S.: SuomiNet: A real-time national GPS network for atmospheric research and education, B. Am. Meteorol. Soc., 81, 677-694, 2000.

Xie, S., Zhang, M., Branson, M., Cederwall, R. T., Del Genio, A. D., Eitzen, Z. A., Ghan, S. J., Iacobellis, S. F., Johnson, K. L., Khairoutdinov, M., Klein, S. A., Krueger, S. K., Lin, W., Lohmann, U., Miller, M. A., Randall, D. A., Somerville, R. C. J., Sud, Y. C., Walker, G. K., Wolf, A., Wu, X., Xu, K.-M., Yio, J. J., Zhang, G., and Zhang, J.: Simulations of midlatitude frontal clouds by SCMs and CSRMs during the ARM March 2000 Cloud IOP, J. Geophys. Res., 110, D15S03, doi:10.1029/2004JD005119, 2005.

Xie, S., Hume, T., Jakob, C., Klein, S., McCoy, R., and Zhang, M.: Observed large-scale structures and diabatic heating and drying profiles during TWP-ICE, J. Climate, 23, 57-79, doi:10.1175/2009JCLI3071.1, 2010.

Xie, S., Zhang, Y., Giangrande, S. E., Jensen, M. P., McCoy, R., and Zhang, M.: Interactions between cumulus convection and its environment as revealed by the MC3E sounding array, J. Geophys. Res., 119, 11784-11808, doi:10.1002/2014JD022011, 2014.

Xu, K.-M., Cederwall, R. T., and Xie, S.: An intercomparison of cloud-resolving models with the ARM summer 1997 IOP data, Q. J. Roy. Meteorol. Soc., 128, 593-624, 2002.

Yanai, M., Esbensen, S., and Chu, J.: Determination of the bulk properties of tropical cloud clusters from large-scale heat and moisture budgets, J. Atmos. Sci., 30, 611-627, 1973.

Yu, H., Ciesielski, P., Wang, J., Kuo, H.-C., Vomel, H., and Dirksen, R.: Evaluation of humidity correction methods for Vaisala RS92 tropical sounding data, J. Atmos. Ocean. Tech., accepted, 2015.

Zhang, M. H. and Lin, J. L.: Constrained variational analysis of sounding data based on column-integrated budgets of mass, heat, moisture and momentum: Approach and application to ARM measurements, J. Atmos. Sci., 54, 1503-1524, 1997.

Zhang, M. H., Lin, J. L., Cederwall, R. T., Yiou, J. J., and Xie, S. C.: Objective analysis of ARM IOP data: Method and sensitivity, Mon. Weather Rev., 129, 295-311, 2001. 